Presented at the 16th International Conference on Infrared and Millimeter Waves. Lausanne, Switzerland, August 26-30, 1991.

\title{
MILLIMETER WAVE FREE ELECTRON LASER AMPLIFIERS: EXPERIMENTS AND DESIGNS*
}

\author{
S. W. Bidwell, Z. X. Zhang, T. M. Antonsen, Jr., D. M. Bensen, \\ W. W. Destler, H. P. Freundt, V. L. Granatstein, \\ P. E. Latham, B. Levush, D. J. Radackt, and J. Rodgers
}

The University of Maryland
Laboratory for Plasma Research
College Park, MD 20742, USA

ABSTRACT
CONF-9108146--2

DE92 011813

Free electron laser amplifiers are investigated as sources of high-average-power ( $1 \mathrm{MW}$ ) millimeter to submillimeter wave radiation $(200 \mathrm{GIz} \cdot 600 \mathrm{G \Pi z})$ for application to electron cyclotron resonance heating of magnetically confined fusion plasmas. As a stepping-stone to higher frequencies and civ operation a pulsed amplifier $\left(\tau_{p u l s e} \simeq 80 \mathrm{~ns}\right.$ ) at $08 \mathrm{GIIz}$ is being developed. Status is reported on this experiment which investigates linear gain amplification with use of a sheet electron beam $\left(\right.$ transverse cross section $\left.=10.1 \mathrm{~cm} \times 2.0 \mathrm{~cm}, V_{\text {beam }}=140 \mathrm{keV}, I_{\text {beam }} \simeq 10 \mathrm{~A}\right)$ and short-period wiggler $\left(l_{w}=0.96 \mathrm{~cm} /\right.$ and with expected output of $140 \mathrm{~W}$. Predictions of gain and efficiency from a 1 . D universal formulation are presented. Beam propagation results, with wiggler focusing as a means of sheet beam confinement in both transverse dimensions, through the $54 \mathrm{~cm}$ (56 period) pulsed electromagnet wiggler are discussed. Peak wiggler ficlds of $5.1 \mathrm{kG}$ on-axis have been achieved.

"Work supported by the U.S. Dept. of Energy, Office of Fusion Energy.

t Science Applications International Corporation, McLean, VA 22102

(1) - 3 INTRODUCTION

MASTER

The liniversity of Maryland is developing a free electron laser (FEL) amplifier for application to electron cyclotron resonance heating (ECRII) and profile control in magretically contined fusion plasmas. Tle auvantages of the FEL include its potential for significant power in the 200 (iIIz to 10)0 (illz range and its inherent tunablity. Development of this source is proceeding in three stages: (1) demonstration of stable, contined sheet electron beam propagation through amplifier relevant wiggier lengths. (2) demonstration of linear gain amplification at 98 GIIz using is sheet electron heam and a short-period wiggler $\left(l_{w}=0.96 \mathrm{~cm}\right)$, and $(3)$ development of a proof-of-principle tapered amplifier at $98 \mathrm{GIIz}$ with parameters (e.g. Pout $\sim 1 \mathrm{MW}, \eta \sim 20 \%$ ) relevant to an eventual source. This short paper will briefly discuss the first two stages of our amplifier development.

\section{SHORT.PERIOD WIGGLER MAGNET AND SHEET BEAM PROPAGATION}

An experimental effort is underway to study sheet electron beam transport through amplifier relevant lengths. Previous work has successfully demonstrated sheet electron beam propagation throunn Mianar ejectromarnet wigglers of modest lengeh.' In particular, propagation through $10 \mathrm{~cm}$ $\left(10\right.$ periods with $\left.I_{w}=1 \mathrm{~cm}\right)$ has shown the wiggler magnet to sufficiently focus a sheet beam $(\sim 500$ $\mathrm{keV}, 7.2 \mathrm{~A},\left(55 \mathrm{~A} / \mathrm{cm}^{2}\right)$, in the narrow transverse dimension and to provide virtually $100 \%$ transport efficiency. To beam instabilities were observed in these approximately $35 \mathrm{~ns}$ pulsed experiments. In contrast to this work, the eventual ECRII source device calls for interaction lengths of $2 \cdot 3 \mathrm{~m}$, and it is toward these lengths that our beam propagation effort is directed.

Similar to our previous magnet designs, the present wiggler consists of copper meander path windings with laminated silicon steel pole pieces. The design employs a two-layer (two turns per pole) configuration which minimizes stray magnetic fields. In particular, stray fields at the wiggler DISTAIBUTIUN OF THIS UOLUMENT IS UNLIMITEM 


\section{DISCLAIMER}

This report was prepared as an account of work sponsored by an agency of the United States Government. Neither the United States Government nor any agency thereof, nor any of their employees, makes any warranty, express or implied, or assumes any legal liability or responsibility for the accuracy, completeness, or usefulness of any information, apparatus, product, or process disclosed, or represents that its use would not infringe privately owned rights. Reference herein to any specific commercial product, process, or service by trade name, trademark, manufacturer, or otherwise does not necessarily constitute or imply its endorsement, recommendation, or favoring by the United States Government or any agency thereof. The views and opinions of authors expressed herein do not necessarily state or reflect those of the United States Government or any agency thereof. 
sides and from the two energizing current feeds are reduced. As a means of increasing the overall interaction length, the wiggler is designed in a modular fashion with 19 periods per module. Three of these modules have been constructed resulting in an overall interaction length of $54 \mathrm{~cm}$ (56 periods). Preliminary measurements indicate up to $5.1 \mathrm{kG}$ pulsed, magnetic fields on-axis. Higher field values are possible since the data indicates that the iron poles have not fully saturated. For an adiabatic beam entrance to the wiggler magnet, we have reduced the volume of iron in the first two wiggler poles. This results in a one-wiggler period entrance taper. Numerical modelling of sheet beam propagation as well as witness plate photos of the beam indicate that this taper is satisfactory. Generation of the sheet electron beam is from a cold (field emission) cathode connected to a pulse-line accelerator. A machined slit within the anode serves to aperture the bearn forming a sheet. Typically, the beam dimensions are $0.1 \mathrm{~cm} \times 2.0 \mathrm{~cm}$.

In the past, at overall interaction lengths of $10 \mathrm{~cm}$, no effort was made to provide for side or wiggle plane focusing. However, for these propagation experiments, with a total length of $54 \mathrm{~cm}$, side focusing can not be ; nored. Our proposed mechanism of side focusing is an offset pole technique. The iron poles, on both the top and bottom wiggler halves, will be alternatively offset in the wide transverse dimension. Measured magnetic field profiles in this dimension indeed indicate a vertical field displacement, with op posite polarity at the two sides. Minimal influence was measured in the central regime of the magnet. It is anticipated, and verified by numerical beam modelling, that this side field displacement will focus straying electrons back into the central region.

\section{TINEAR GAIN AMPLIFIER AT 08 GIIZ}

An amplifier is under development which is intended to demonstrate linear gain at $98 \mathrm{GHz}$ and which will employ the short-period electromagnet wiggler discussed above. Parameters for this pulsed amplifier as well as a design for a cw ECRII source are given in Table 1 . A peak power of $140 \mathrm{~W}$ is anticipated, as predicted by a $1-\mathrm{D}$ universal formulation ${ }^{2}$, after $5.4 \mathrm{~cm}$ of interaction length.

\begin{tabular}{|c|c|c|}
\hline & $1 \mathrm{~cm}$ Viegles & Design Gioal \\
\hline frequency $(\mathrm{GIJz})$ & 98 & 2so \\
\hline Vinom (IIIV) & 0.44 & 1.0 \\
\hline$I_{\text {brom }}(\lambda)$ & 10.0 & 5.8 \\
\hline$S_{\text {tomom }}\left(\mathrm{cm}^{2}\right)$ & $0.1 \times 2.0$ & $0.1 \times 2.0$ \\
\hline$B_{w, 0}(h())$ & 3.4 & 10.0 \\
\hline $1 .(m \cdot n)$ & 9.6 & 10.5 \\
\hline$a_{w 0}$ & 030 & 0.98 \\
\hline$S_{w},\left(\mathrm{~cm}^{2}\right)$ & $0.32 \times 4.0$ & $0.52 \times 3.0$ \\
\hline$P(W) 95 . \mathrm{cm}$ & $110^{\circ}$ & - \\
\hline 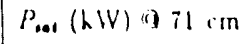 & - & Cis 1 \\
\hline Gain $(d B / \mathrm{cm})$ & 0.39 & 0.26 \\
\hline
\end{tabular}

Table 1: Parameters of the lincar gain amplifier at $98 \mathrm{GIIz}$ and, for comparison, a design goal for ECRII application.

\section{REFERENCES}

1) D. J. Radack, J. I. Booske, Y. Carmel, and W. W. Destler, Appl. Phys. Lett. 55 (1989) 2069.

2) J. H. Booske, S. IV. Bidwell, B. Levush, T. M. Antonsen, Jr., and V. L. Granatstein, J. Appl. Phys. 69 (1991) 7503. 

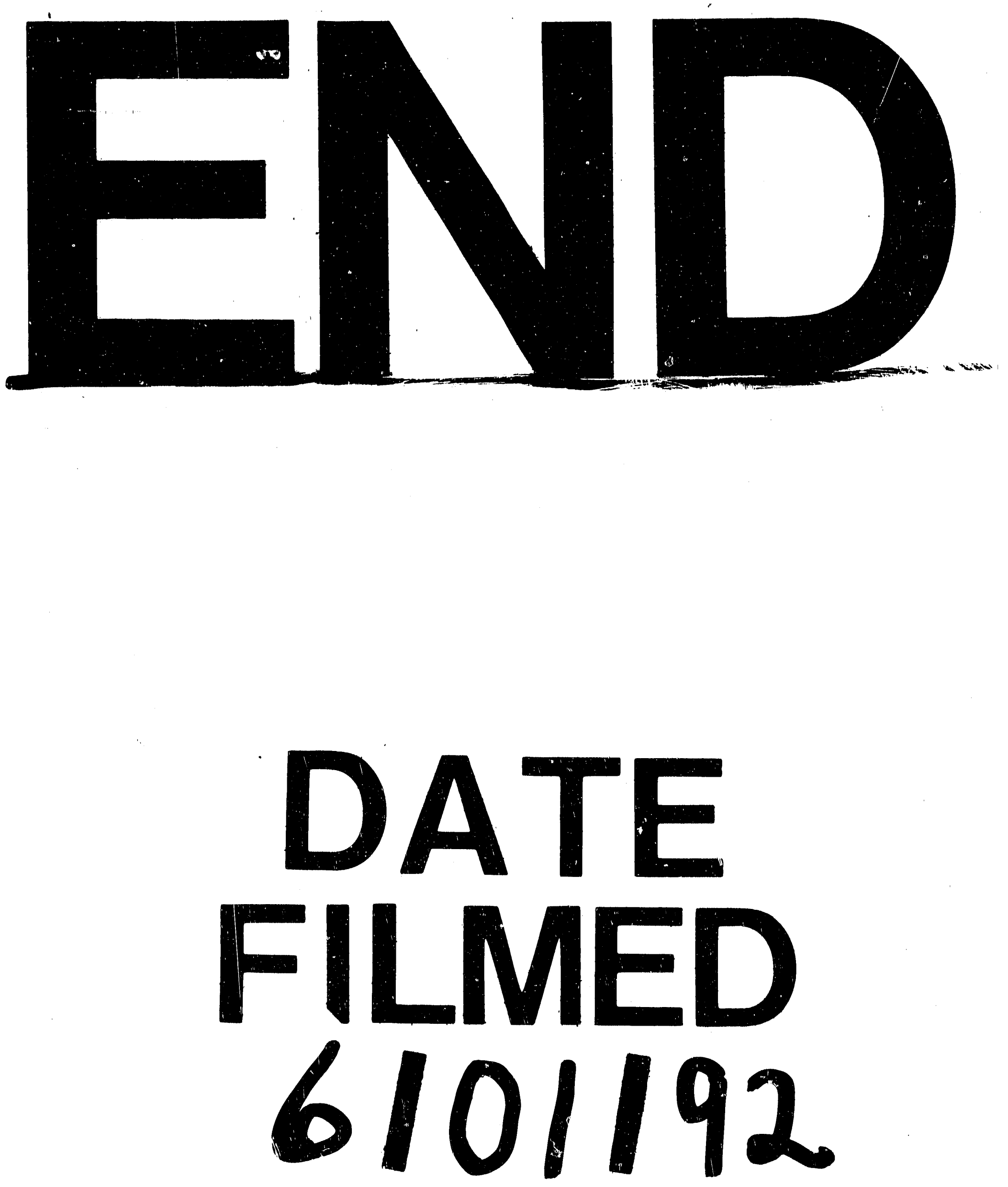

1 
